\title{
BLOOMS OF TOXIC CYANOBACTERIA IN FRESHWATER IN ALGERIA
}

\author{
Hichem Nasri ${ }^{1 *}$ and Noureddine Bouaïcha ${ }^{2}$ \\ ${ }^{1}$ Laboratory of Biodiversity and pollution of Ecosystems, Department of Biology, University of El Taref, El Taref, Algeria. \\ ${ }^{2}$ Laboratory of «Ecologie, Systématique et Evolution », UMR 8079, 5, Rue J.B. Clement, University of Paris-Sud 11, Bâtiment 362, \\ 91405 OrsayCedex, France. \\ *Corresponding Author E-mail: Nasri_cyanobacteria@yahoo.fr
}

This is an open access article distributed under the Creative Commons Attribution License, which permits unrestricted use, distribution, and reproduction in any medium, provided the original work is properly cited

\section{ARTICLE DETAILS}

\section{Article history:}

Received 12 October 2017

Accepted 12 November 2017

Available online 20 Disember 2017

Keywords:

Cyanobacteria, Lake Oubeira, Dam Cheffia, Algeria

\section{ABSTRACT}

When water temperature and irradiance as well as meteorological conditions and nutrient supply are favourable, cyanobacteria can flourish in lakes and rivers where they can produce blooms usually in summer to late autumn, in both subtropical and temperate latitudes. Several of which are toxic and produce specifically hepatotoxins type microcyst ins. Studies undertaken in dams and natural lakes, particularly in the lake Oubeira and the dam Cheffia (East-Algeria), showed that these media evolve quickly to eutrophication, following an increased productivity stimulated continuously by the fertilizer contributions and a change of increasingly dry climate. The appearance of toxic cyanobacteria in these water bodies either used as drinking water or for recreational purposes may present serious health risks for the human population. The biodiversity of toxic cyanobacteria and their toxins, undertaken in the lake Oubeira and the dam Cheffia, showed that the Microcystic is the most implied genus in the formation of cyanobacterial blooms. The concentrations of microcyst ins, estimated by the PP2A method, are very high (28 mg/L) during the period of cyanobacterial blooms in summer and the beginning of autumn. The MC-LR, MC-YR, and MCRR are the most common microcyst in congeners identified in these water bodies.

\section{INTRODUCTION}

In recent years, the incidence of harmful algal blooms in aquatic ecosystems has increased globally in frequency, severity, and duration [1]. The cause for this apparent expansion is unknown, but numerous studies suggest that eutrophication and climate change are two processes that may promote the proliferation and expansion of harmful cyanobacterial blooms [2]. Therefore, in the African continent, it is most probable that these changes in climate associated to the pressures cumulating by many activities such as tourist industry and urbanization in the cost line of some countries will trigger the trend towards continuous degradation of the water quality. In addition to continuous degradation of their coastal areas, the North African arid countries are identified with serious future limitations for water quality and quantity. Consequently, on their efforts to overcome these issues and to support their economic and social development, certain countries such as Algeria with resources which do not exceed an average of 1000 cubic meters per year and per inhabitant supplied important efforts of mobilization of the superficial water resources by construction of dams. However, in these reservoirs and natural lakes which are also fragile and of high ecological, social and cultural value; the discharge of sewage, industrial pollutants, eroding soil, and deposition of effluents rich in nitrates and phosphorus potentiate the development of some toxic cyanobacteria species [3].

During the last decade, the purpose of our research was focused on the biodiversity of cyanobacteria and their toxins in the Cheffia dam and Oubeira lake. The Cheffia Dam is located in the Wilaya of El Tarf in the north-eastern Algeria with the coordinates of $36^{\circ} 07^{\prime} \mathrm{N}$ and $8^{\circ} 03^{\prime} \mathrm{E}$. It covers 1000 hectares and has a maximum depth of $30 \mathrm{~m}$, and it provides drinking water for the Wilaya of Annaba and the surrounding area (population 1 million). However, Lake Oubeira is a shallow, polymictic waterbody, located in north-eastern Algeria $\left(36^{\circ} 53 \mathrm{~N}\right.$ and $\left.008^{\circ} 23 \mathrm{E}\right)$, home to El Kala National Park, and has an average elevation of $25 \mathrm{~m}$ above sea level. It is the first largest freshwater lake in Algeria and has an estimated surface area of 2,200 ha and a maximum depth of $4 \mathrm{~m}$. In 1984, the lake was included as a wetland under the Ramsar Convention [Ramsar Convention Official Website (www.ramsar.org)] because it is considered an important natural reserve for migratory birds and wildfowl species.

Fishing and irrigation are some of the activities practiced in and around its waters.

\section{BIODIVERSITY OF TOXIC CYANOBACTERIA AND THEIR TOXINS IN} THE SURFACE WATERS OF THE NORTHEAST ALGERIAN

In the surface waters of the northeast Algerian, several studies have shown that cyanobacterial blooms containing microcyst ins were dominated by the genus Microcystic $[4,5,6,7,8,9]$. Our investigation in the Cheffia dam has shown that this reservoir has seasonal cyanobacterial blooms that start in summer and last into autumn, however Lake Oubeira has persistent blooms that encompass all seasons. Cyanobacteria have a cosmopolitan distribution and colonize a great variety of ecosystems, but they are especially associated with water bodies such as rivers, lakes and dams. Favourable cyanobacterial growth conditions that often lead to blooms usually in summer to late autumn, in both subtropical and temperate latitudes are a combination of abiotic factors (water stratification, high light intensity and temperature, alkaline $\mathrm{pH}$ and water eutrophication) and biotic factors (zooplankton grazing) [3]. Maximum growth rates are attained by most cyanobacteria at temperatures above $25^{\circ} \mathrm{C}$. For example, within these two surface waters cyanobacterial blooms have been observed during the warmest months particularly in summer and in early autumn waters $[5]$.

Total microcyst in concentrations in the raw water of the Cheffia dam reached a level of $28.9 \mu \mathrm{g} / \mathrm{L}$ MCYST-LR equivalent and were significantly correlated to cyanobacterial biomass. The LC/MS/MS analysis of cyanobacterial extract prepared from the raw water sample, in which the highest microcyst in concentration is observed, revealed the presence of two microcyst in variants: microcyst in-YR (MCYSTYR) and microcyst inLR (MCYST-LR), [5]. However, in the lake Oubeirathe high concentration of microcyst ins was detected in autumn 2004 at $29 \mathrm{mg}$ equivalent MC-LR/l [4]. Analysis of the field bloom extract from this Lake by MALDI-TOF mass spectrometry demonstrated the presence of four variants of microcystins: microcystin-LR (MCYST-LR), microcystin-YR (MCYSTYR), microcystin-RR (MCYST-RR), and a demethylated variant of MCYST-LR (DMCYST-LR). Recently, analysis of a cyanobacterial bloom dominated by the genus Microcystis and harvested from the lake des Oiseaux, near the lake Oubeira,revealed the presence of a high diversity of microcystin variants with 21 congeners identified. Among these, 12 known microcystins (MCRR, MC-LR, MC-FR, MC-WR, MC-YR, MC-LA, MC(H4) YR, MC-HilR, [Asp3] MCRAba, and [Glu(OCH3)6]MC-LR) and two new congeners ([Asp3]MCHarAba and [Glu(OCH3)6]MC-FR) were characterized. The variant MC-RR was the major (43.4\%) in the blood sample [9]. 
The contamination of surface water by these cyanotoxins can cause water quality problems for fisheries, aquaculture, farming, and sanitary hazard for human and animals. Consequently, Humans and other animals can be indeed exposed to cyanotoxins through both direct routes, including contamination of drinking and recreational waters, and indirect routes, including food supplements made from cyanobacteria, or through consumption of contaminated food after toxin accumulation in fish, shellfish and other aquatic organisms, as well as in vegetables after using contaminated water for irrigation [10]. For example, a research paper reported that the common carp caught in Lake Oubeira (Algeria) between April 2010 and March 2011 have concentrations of microcystins in their muscle tissues exceeding 2.75.7 times the WHO-TDI guideline [11]. Microcystins have adverse effects also on aquatic fauna, which are directly exposed. For example, a scientist reported for the first time the mortality of freshwater turtles associated to a toxic bloom of Microcystis sp. producing MCs in Lake Oubeira (Algeria).

\section{CONCLUSION}

These studies showed in dams and natural lakes located in the Northeast of Algeria the dominance of the genus Microcystis in autumn with high microcystin concentrations reaching $29 \mathrm{mg}$ equivalent MCLR/L.High diversity of microcystin variants was also observed with the MC-LR, the high toxic congener, was usually the major in the blood samples. Consequently, the presence of these toxins in these surface waters constitutes a considerable potential risk to human and animals, especially during the period of development of cyanobacterial blooms.

\section{REFERENCES}

[1]Chorus, I., and Bartram, J. 1999. Toxic cyanobacteria in water: a guide to public health significance, monitoring and management. Spon London, 416.

[2]0'Neil, J., Davis, T., Burford, M., Gobler, C. 2012. The rise of harmful cyanobacteria blooms: the potential roles of eutrophication and climate change. Harmful Algae, 14, 313-334.

[3]El Herry-Allani, S., Bouaïcha, N. 2013. Cyanobacterial blooms in dams: environmental factors, toxins, public health, and remedial measures. In: Khlifi, S. (Ed.), Dams: Structure, Performance and Safety Management. Nova Science Publishers Inc., New York, 227e264.

[4] Nasri, A.B., Bouaïcha, N., and Fastner, J. 2004. First report of a microcystin containing bloom of the cyanobacteria Microcystis spp. in Lake Oubeira, Eastern Algeria. Archives of Environmental Contamination and Toxicology, 46, 197-202.

[5] Nasri, H., Bouaïcha, N., KaidHarche, M. 2007. A new morphospecies of Microcystis sp. forming bloom in the Cheffia Dam (Algeria): seasonal variation of microcystin concentrations in the raw water and their removal in a full-scale treatment plant. Environmental Toxicology, 22, $347-356$.

[6] Nasri, H., El Herry, S., and Bouai"cha, N. 2008. First reported case of turtle deaths during a toxic Microcystis spp. bloom in Lake Oubeira, Algeria. Ecotoxicology and Environmental Safety, 71, 535-544.

[7] El Herry, S., Fathalli, A., Jenhani Ben Rejeb, A., Bouaïcha, N., 2009. Seasonal occurrence and toxicity of Microcystis spp. and Oscillatoria tenuis in the Lebna dam, Tunisia. Water Research, 42, 1263e1273.

[8] Ouartsi, A., Saoudi, A., and Chekireb, D. 2011. Etude des efflorescences toxiques à Cyanobactéries dans le Barrage Mexa, Algérie. Review of Industrial Microbiology Sanitary and Environnemental, 5 (1), 81-100.

[9] Bouhaddada, R., Nélieu, S., Nasri, H., Delarue, G., and Bouaïcha, N. 2016. High diversity in a Microcystis bloom from Algerian lake. Environmental Pollution, 216, 836-844.

[10] Ettoumi A., El Khalloufi, F., El Ghazali, I., Oudra, B., Amrani, A., Nasri H., and Bouaïcha, N. 2011. Bioaccumulation of Cyanobacterial Toxins in Aquatic Organisms and its Consequences for Public Health. Chapter In: Zooplankton and Phytoplankton. Editor: Giri Kattel, pp., Nova Science Publishers, Inc.

[11] Amrani, A., Nasri, H., Azzouz, A., Kadi, Y., and Bouaïcha N. 2014. Variation in nCyanobacterial Hepatotoxin (Microcystin) Content of Water Samples and Two Species of Fishes Collected from a Shallow Lake in Algeria. Archives of Environmental Contamination and Toxicology, 66 (1).. 